\title{
At-a-glance
}

\section{Emergency department surveillance of thermal burns and scalds, electronic Canadian Hospitals Injury Reporting and Prevention Program, 2013}

\author{
Jennifer Crain, MA (1); Steven McFaull, MSc (1); Deepa P. Rao, PhD (1); Minh T. Do, PhD (1,2); \\ Wendy Thompson, MSc (1)
}

Tweet this article

\section{Introduction}

Although fatality and hospitalization rates for burns in Canada have declined over time, ${ }^{1,2}$ less serious cases still commonly present to the emergency department (ED).

\section{Methods}

The Canadian Hospitals Injury Reporting and Prevention Program (CHIRPP) is an injury and poisoning surveillance system administered by the Public Health Agency of Canada, operating in emergency departments of 17 hospitals. ${ }^{3}$ We searched the electronic CHIRPP (eCHIRPP) database for ED visits by people of all ages for thermal burns and scalds sustained in 2013. Burns from friction, chemical/caustic agents, and direct contact with lightning were excluded because they present unique circumstances.

\section{Results}

Overall, 1682 cases were identified, representing $1.2 \%(1682 / 137245 ; 1226 / 100000$ eCHIRPP cases) of injuries reported in 2013. Half were scalds $(52.3 \%$; 879/1682) and $29.9 \%(503 / 1682)$ were contact burns from hot objects (Figure 1). The two leading direct causes of scalds were hot beverages at $34.1 \%(292 / 856 ; \mathrm{n}=23$ missing $)$ and hot water (not from the tap) at $28.9 \%$ (247/856; $\mathrm{n}=23$ missing). The two leading direct causes of contact burns were stoves/ovens $(22.0 \%$; $109 / 495 ; n=8$ missing), and fireplaces/accessories (19.6\%; 97/495; $\mathrm{n}=8$ missing). Overall, $13.0 \%$ of

cases $(218 / 1682)$ were serious enough to require hospital admission; the highest proportion of hospitalizations was among those exposed to fire/flame/smoke, at $38.9 \%(72 / 185)$.

FIGURE 1

Distribution of burn injuries by mechanism, frequency and percent, all ages, eCHIRPP 2013

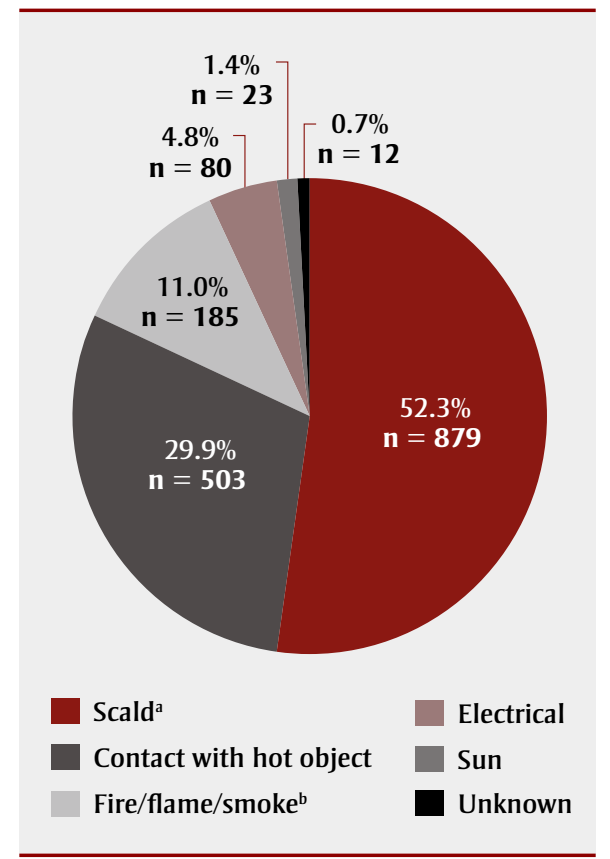

Abbreviation: eCHIRPP, electronic Canadian Hospitals Injury Reporting and Prevention Program.

a Includes contact with hot water, steam, food, oil, grease, liquid glue and liquid wax.

${ }^{\mathrm{b}}$ Includes explosions and contact with hot coals.
While the overall proportion of burns was highest among females, males comprised a higher proportion of burns from all mechanisms except scalds (Table 1). Figures 2 and 3 show age and sex distributions among scalds and contact burns, respectively. Young children were the most prominent age group for both types of burn.

Among burns from fire/flame/smoke, the highest proportion based on age and sex was within males aged 50 to 64 years ( $\mathrm{n}=16 ; 782 / 100000$ eCHIRPP cases), whereas the highest count was among males aged 15 to 19 years $(n=21 ; 209.1 / 100000$

TABLE 1

Distribution of burns by mechanism and sex, proportion per 100000 records, ${ }^{\text {a }}$ eCHIRPP 2013

\begin{tabular}{lrc} 
Thermal mechanism & Males & Females \\
\hline Scald & 544.7 & 767.4 \\
\hline Hot object & 393.5 & 331.3 \\
\hline Fire/flame/smoke $^{\mathrm{b}}$ & 169.2 & 89.6 \\
\hline Electrical & 71.8 & 40.6 \\
\hline Sun & 20.5 & 11.8 \\
\hline Unknown & 7.7 & 10.1 \\
\hline Total & 1207.4 & 1250.8 \\
\hline
\end{tabular}

Abbreviation: eCHIRPP, electronic Canadian Hospitals Injury Reporting and Prevention Program.

a Per 100000 eCHIRPP cases of all injury types among the same sex.

${ }^{\mathrm{b}}$ Includes explosions and contact with hot coals. 
FIGURE 2

Distribution of scalds $s^{\mathrm{a}}$ by age group and sex, frequency and proportion per $100 \mathbf{0 0 0}^{\mathrm{b}}$ records, eCHIRPP 2013

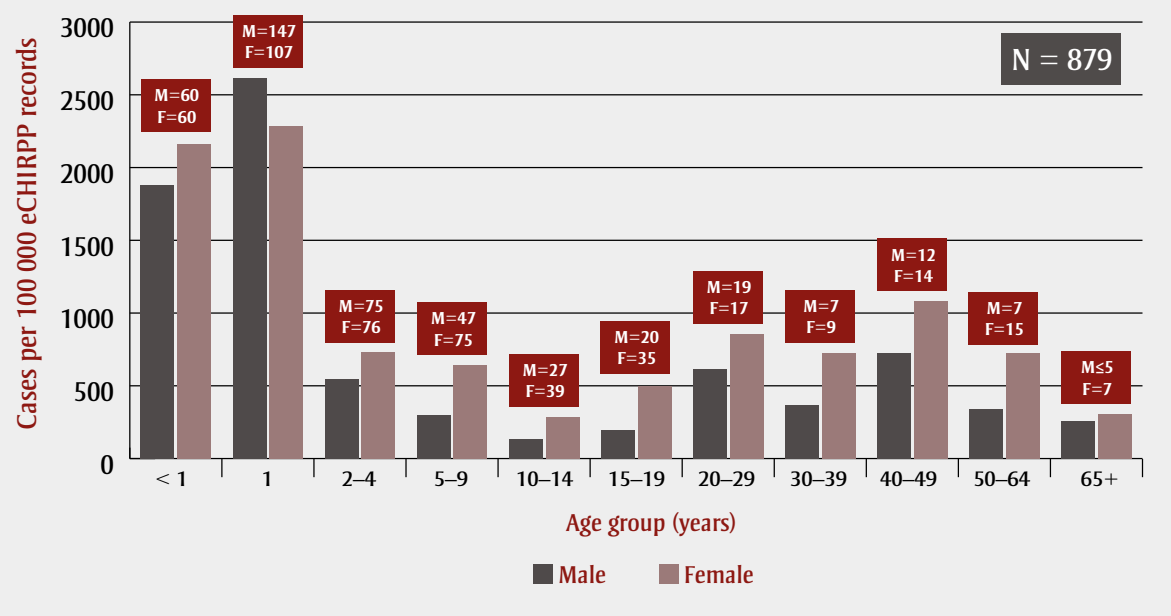

Abbreviation: eCHIRPP, electronic Canadian Hospitals Injury Reporting and Prevention Program; F, females; M, males.

Note: The coloured bars represent the proportion of males/females involved in scaldings per 100000 eCHIRPP injuries of all types.

${ }^{a}$ Includes contact with hot water, steam, food, oil, grease, liquid glue or liquid wax.

${ }^{\mathrm{b}}$ Per 100000 eCHIRPP cases of all injury types within the specified age group and sex.

eCHIRPP cases). The highest proportion of burns from fire/flame/smoke among females occurred among those aged 20 to 29 years $(\mathrm{n}=6 ; 302.3 / 100000$ eCHIRPP cases).

Males and females aged 20 to 29 years shared the highest proportions of sun burns (64.8 and 151.1/100 000 eCHIRPP

FIGURE 3

Distribution of burns from contact with hot objects, by age group and sex, frequency and proportion per $100000^{\mathrm{a}}$ records, eCHIRPP 2013

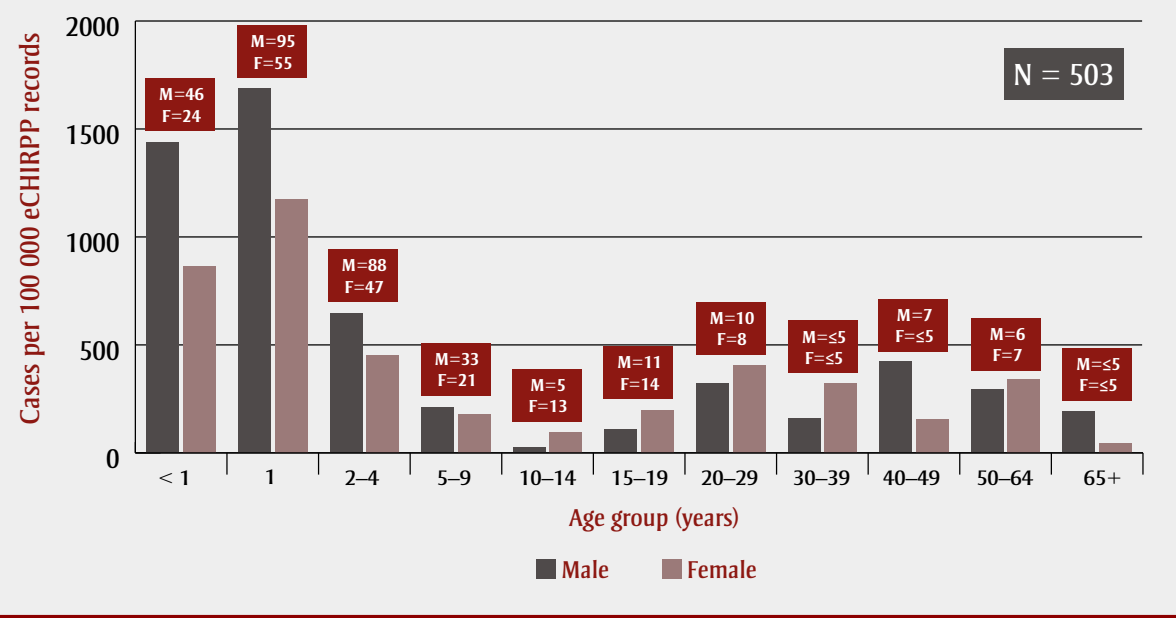

Abbreviations: eCHIRPP, electronic Canadian Hospitals Injury Reporting and Prevention Program; F, females; M, males.

Note: The coloured bars represent the proportion of males/females involved in scaldings per $100000 \mathrm{eCHIRPP}$ injuries of all types.

${ }^{a}$ Per 100000 eCHIRPP cases of all injury types within the specified age group and sex.

\section{Discussion}

Burns appear consistently in the CHIRPP. The high proportion of scalds and contact burns to young children points to social and biological risk factors, including more time spent at home (where most burns occur), and younger, thinner skin that is more prone to burning. Improved awareness of these risk factors and appropriate safety measures is recommended.

\section{Limitations}

The results for less common burn mechanisms may be subject to random variation due to small sample sizes. The cases described also do not represent all thermal burns and scalds in Canada, as only some hospitals participate in the CHIRPP. Along with older teens and adults, Aboriginal persons and rural inhabitants are underrepresented because most CHIRPP sites are pediatric hospitals in major cities. Fatalities are also underrepresented because emergency department data do not capture people who died before being taken to hospital or after being admitted.

\section{References}

1. Statistics Canada. CANSIM database: Table 102-0552: Deaths and mortality rate, by selected grouped causes and sex, Canada, provinces and territories, annual [Internet]. Ottawa $(\mathrm{ON})$ : Statistics Canada; [modified 2015 Dec 09; cited August 17, 2016]. Available from: http://www5.statcan.gc.ca /cansim/a26?lang = eng\&id $=1020552$

2. Public Health Agency of Canada. Injury in Review, 2012 Edition: Spotlight on Road and Transport Safety. Ottawa (ON): Public Health Agency of Canada; 2012 [Catalogue No. HP15-14/2012E-PDF].

3. Crain J, McFaull S, Thompson W, Skinner R, Do MT, Fréchette $M$, Mukhi S. Status report: the Canadian Hospitals Injury Reporting and Prevention Program: a dynamic and innovative injury surveillance system. Health Promot Chronic Dis Prev Can. 2016;36(6):112-117. 